\title{
The Novel Long Noncoding RNA TUSC7 Inhibits Proliferation by Sponging MiR-211 in Colorectal Cancer
}

\author{
Jian Xu Jian Zhao Rui Zhang \\ Department of Colorectal Surgery, Cancer Hospital of China Medical University, Liaoning Cancer \\ Hospital \& Institute, Shenyang, China
}

\section{Key Words}

Long noncoding RNA • TUSC7 • MiR-211-3p • CDK6 • Colorectal cancer • CeRNA

\begin{abstract}
Background/Aims: The novel long noncoding RNA (IncRNA) tumor suppressor candidate 7 (TUSC7) has been reported as a potential tumor suppressor, while the functional role of TUSC7 is still unknown in colorectal cancer (CRC). Here, we characterized TUSC7 expression profile in CRC patients and investigated its biological function and potential molecular mechanism. Methods: RNA isolation, qRT-PCR, cell counter kit- 8 assay, cell cycle assay, EdU assay, and western blot were performed. Statistical analyses were performed using SPSS 18.0 software and $p$ value $<0.05$ was considered as statistically significant. Results: In a cohort of CRC patients, we found TUSC7 was significantly downregulated in CRC tissues compared with adjacent non-tumor tissues $(P<0.01)$. Patients with high expression of TUSC7 had better survival than those with low expression of TUSC7 (HR $=0.342,95 \%$ CI: $0.120-0.972, P=0.044$ ). Cell count kit 8 and EdU assays showed that ectopic expression of TUSC7 in HCT116 and SW480 cells significantly inhibited cell proliferation rate. After silence of TUSC7 with small interfering RNA, cell proliferation rate increased. Flow cytometry analyses revealed cycles were arrested at G1 phase after TUSC7 overexpression. We found there were 2 binding sites of miR211-3p within the sequence of TUSC7 and TUSC7 expression level was negatively correlated with miR-211-3p. TUSC7 overexpression increased the expression level of CDK6, which is a downstream target of miR-211-3p, in both RNA and protein level. Furthermore, luciferase reporter assay indicated that TUSC7 could sponge miR-211-3p. Conclusion: To summary, we demonstrated that TUSC7 is a potential tumor suppressor in CRC, and TUSC7 could inhibit CRC cell proliferation by completely sponging miR-211-3p.
\end{abstract}

(C) 2017 The Author(s)

Published by S. Karger AG, Basel

\section{Introduction}

Colorectal cancer (CRC) is one of the most common kinds of cancer worldwide, of which the incidence rate ranks the third in male and the second in female $[1,2]$. The survival of CRC patients at early stage has improved in the last decades, while the prognosis of patients with 


\section{Cellular Physiology Cell Physiol Biochem 2017;41:635-644

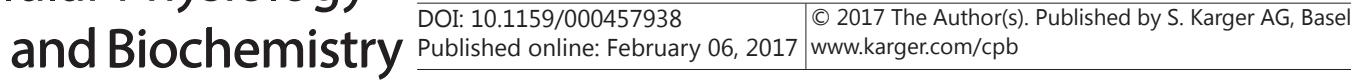 \\ Xu/Zhao/Zhang: TUSC7 Sponges MiR-211-3p in CRC}

advanced stages remains poor $[3,4]$. Therefore, there is a definite need for more effective treatment methods and innovative biological targets.

Recent evidence has proved that noncoding RNAs, especially microRNAs (miRNAs) and long noncoding RNAs (lncRNAs) are deeply involved in the processes of cancer initiation and progression [5-9]. LncRNA is a kind of RNA transcripts larger than 200nt and without protein-coding capacity [5]. According to the transcription direction with nearby coding genes, IncRNA could be classified into 5 groups: sense, antisense, intergeneic, intronic, and bidirectional [5]. miRNAs are a class of highly conserved RNA molecules that negatively regulate gene expression by binding to the 3'-untranslated region (3'UTR) of target mRNAs [10]. Many lncRNAs and miRNAs have been characterized in CRC, as oncogenes or tumor suppressors. For example, colon cancer associated transcript 2 (CCAT2) is a wellknown oncogenes and CCAT2 is reported to promote CRC tumor growth, metastasis, and chromosomal instability [11]. Recent evidence has suggested that lncRNA transcripts could "talk" with mRNAs if they have the same microRNA binding sites, namely the competing endogenous RNA (ceRNA) hypothesis.

Tumor suppressor candidate 7 (TUSC7) is a 2105nt intergeneic lncRNA, located in the chromosome region of 3q13.31. Previous reports showed that TUSC7 could inhibit proliferation in and play as tumor suppressor in osteosarcoma and gastric cancer $[12,13]$. However, little is known about the role of TUSC7 in CRC. In the current study, we analyzed expression of TUSC7 in CRC and found TUSC7 could inhibit proliferation of CRC cells by sponging miRNA-211-3p in the ceRNA manner.

\section{Materials and Methods}

Patients and tissue samples

The study was approved by the Ethics Committee of the Liaoning Cancer Hospital. Written informed consent was obtained from every patient. A total of 63 pairs of primary CRC tissues and adjacent normal tissues were collected from patients who underwent surgery at the Department of Colorectal Surgery, the Liaoning Cancer Hospital between 2008 and 2011. After removal from the resected esophagus, the tumor samples were collected immediately and then frozen stored at liquid nitrogen till RNA extraction. All tumor specimens and paired normal tissues were confirmed by experienced pathologists. The clinical and pathological characteristics of each patient were also collected.

\section{Cell lines and culture conditions}

All cell lines were obtained from Shanghai Institutes for Biological Science, China. All cells were grown in RPMI 1640 medium (GIBICO-BRL), supplemented with penicillin-streptomycin (Invitrogen, Shanghai, China) and $10 \%$ FBS (Life Technologies, Australia). All cells were grown in in an incubator at $37^{\circ} \mathrm{C}$ with $5 \%$ $\mathrm{CO}_{2}$.

\section{RNA extraction and $q R T-P C R$ analysis}

Total RNA was isolated with TRIzol reagent (Invitrogen, Carlsbad, CA, USA) according to the manufacturer's protocol. $500 \mathrm{ng}$ total RNA was reverse transcribed in a final volume of $10 \mu \mathrm{l}$ using random primers under standard conditions using the PrimeScript RT Master Mix (TaKaRa, Dalian, China). The PrimeScript RT reagent Kit and SYBR Premix Ex Taq (TaKaRa, Dalian, China) was used for quantitative real-time polymerase chain reaction (qRT-PCR) according to the manufacturer's instructions. GAPDH was measured as an internal control, as its expression showed minimal variation in different cell lines and cancer specimens. The PCR primers used were as follows: TUSC7 sense, 5'-GGAAACAGAAGGCACCTCA-3' and reverse, 5'-TCTCAGAGGTCAAACAGGCA-3'; GAPDH sense, 5'-GTCAACGGATTTGGTCTGTATT-3' and reverse, 5'-AGTCTTCTGGGTGGCAGTGAT-3'; small nuclear RNA U1 sense, 5'- GGGAGATACCATGATCACGAAGGT-3' and reverse 5'-CCACAAATTATGCAGTCGAGTTTCCC-3'. For miR-211-3p reverse transcription and PCR analysis, primers were purchased from (Ribobio, Guangzhou, China). The PCR reaction was conducted at $95^{\circ} \mathrm{C}$ for 30 $\mathrm{s}$ and followed by 40 cycles of $95^{\circ} \mathrm{C}$ for $5 \mathrm{~s}$ and $60^{\circ} \mathrm{C}$ for $34 \mathrm{~s}$ in the ABI 7500 real-time PCR system (Applied 


\section{Cellular Physiology Cell Physiol Biochem 2017;41:635-644 \begin{tabular}{ll|l} 
and Biochemistry & $\begin{array}{l}\text { DOI: 10.1159/000457938 } \\
\text { Publisned onlne: February 06, } 2017\end{array}$ & $\begin{array}{l}\text { O 2017 The Author(s). Published by S. Karger AG, Basel } \\
\text { www.karger.com/cpb }\end{array}$ \\
\cline { 2 - 3 }
\end{tabular} \\ Xu/Zhao/Zhang: TUSC7 Sponges MiR-211-3p in CRC}

Biosystems, Foster City, CA, USA). The Ct value for each sample was calculated with the $\Delta \Delta \mathrm{Ct}$ method, and expression fold changes (tumor vs. normal) were calculated using $2^{-\Delta \Delta C T}$ methods [14].

\section{Plasmid construction}

The sequence of TUSC7 (http://www.ncbi.nlm.nih.gov/nuccore/213417754?report=fasta) was synthesized and subcloned into pcDNA3.1 (Invitrogen, Shanghai, China). Ectopic expression of TUSC7 was achieved by using the TUSC7 plasmid transfection and empty pCDNA vector (EV) was used as control. The expression level of TUSC7 was detected by qPCR.

\section{Transfection of CRC cells}

All plasmid vectors (TUSC7 and EV) for transfection were extracted by DNA Midiprep or Midiprep kit (Qiagen, Hilden, Germany). HCT116 and SW480 cells cultured on six-well plate were transfected with the TUSC7 or EV using Lipofectamine2000 (Invitrogen, Shanghai, China) according to the manufacturer's instructions. MiR-211-3p mimic and negative control (NC) were designed and synthesized by Life Technology, followed with transfection by Lipofectamine2000 reagent according to the procedure. Small interfering RNA sequences targeting TUSC7 or negative control were transfected using Lipofectamine2000 according to the manufacturer's instructions. The siRNA sequences were as follows: siRNA1 5'- CCAGAAAGAUAUCAACAAAUU-3', siRNA2 5'- GGAGAUAUAUCUUGCUAGAGG-3', siRNA3 5'-AGAUUUCAGUGGUAUUGUAUA-3'. Cells were harvested after 48 hours for qRT-PCR and western blot analyses.

\section{Cell fraction assay}

The cell fraction assay was performed using the PARIS Kit (Life Technologies, Carlsbad, CA, USA) according to the manufacturer's instructions and small nuclear RNA U1 (snRNA U1) was used as a positive control for nucleus and GADPH was used a positive control for cytoplasm.

\section{Cell Counting Kit-8 assay}

Cell proliferation was monitored by the Cell Counting Kit-8 (CCK8) assay (Promega) every $24 \mathrm{~h}$ following the manufacturer's protocol. In brief, the transfected cells were plated in 96-well plates (3000 cells/well), and then $10 \mu \mathrm{l}$ of CCK8 solution was added and incubated for $2 \mathrm{~h}$. Each solution was measured spectrophotometrically at $450 \mathrm{~nm}$.

\section{Ethynyldeoxyuridine (EdU) analysis}

5-ethynyl-2-deoxyuridine (EdU) labeling/detection kit (Ribobio, Guangzhou, China) was used to assess the cell proliferation. Cells were grown in 96 -well plates at $5 \times 10^{3}$ cells/well. Forty-eight hours after transfection, $50 \mu \mathrm{M}$ EdU labeling media was added to the 96-well plates and they were incubated for $2 \mathrm{~h}$ at $37^{\circ} \mathrm{C}$ under $5 \% \mathrm{CO}_{2}$. After treatment with $4 \%$ paraformaldehyde and $0.5 \%$ Triton X-100, cells were stained with anti-EdU working solution. DAPI was used to label cell nuclei. The percentage of EdU-positive cells was calculated after analyses of fluorescent microscopy. Five fields of view were randomly assessed for each treatment group.

\section{Colony Formation assay}

For colony formation assay, 200 cells were seeded in a six-well plate and maintained in media containing $10 \%$ FBS, replacing the medium every 4 days. After 14 days, cells were fixed with methanol and stained with $0.1 \%$ crystal violet. Visible colonies were manually counted. Triplicate wells were measured for each treatment group.

\section{Matrigel Assay}

To investigate invasion ability of CRC cells, matrigel assay was performed. Transfected cells $\left(4 \times 10^{5}\right)$ were plated in the top chamber with a Matrigel-coated membrane (BD Biosciences) in 300- $\mu$ l serum-free RPMI 1640 accompanied with $500 \mu \mathrm{l} 10 \%$ FBS-RPMI 1640 in the bottom chambers. After a48-h incubation period, we determined the invasion function as mentioned previously in migration. 


\section{Cellular Physiology Cell Physiol Biochem 2017;41:635-644 \begin{tabular}{ll|l} 
and Biochemistry Published ontIne: February 06, 2017 & $\begin{array}{l}\text { (C) } 2017 \text { The Author(s). Published by S. Karger AG, Basel } \\
\text { www.karger.com/cpb }\end{array}$ \\
\hline
\end{tabular} \\ Xu/Zhao/Zhang: TUSC7 Sponges MiR-211-3p in CRC}

Flow-cytometric analysis

Cells transfected with TUSC7 and EV were harvested 48 hours after transfection by trypsinization. Cells for cell-cycle analysis were stained with propidium iodide by the Cycle TEST PLUS DNA Reagent Kit (BD Biosciences) following the protocol and analyzed by FACScan. The percentage of the cells in G0-G1, S, and G2-M phase were counted and compared. All of the samples assayed were in triplicates.

Western blotting assay

Cells were lysed using mammalian protein extraction reagent RIPA (Beyotime china) supplemented with protease inhibitors cocktail (Roche, Switzerland) and PMSF (Roche, Switzerland). Protein concentration was measured with the Bio-Rad protein assay kit. $50 \mu$ g protein extractions were separated by $12 \%$ SDSpolyacrylamide gel electrophoresis (SDS-PAGE), then transferred to $0.22 \mu \mathrm{m}$ nitrocellulose membranes (Sigma-Aldrich. USA) and incubated with specific antibodies. ECL chromogenic substrate was used to visualize the bands and the intensity of the bands was quantified by densitometry (Quantity One software; Bio-Rad). GAPDH was used as control. GAPDH antibody was purchased from sigma-Aldrich (USA), and CDK6 antibody was purchased from Santa Cruz Biotechnology (Santa Cruz, CA, USA).

Luciferase assays

The 3'-UTR of CDK6 was amplified and cloned into the pMIR-REPORT reporter plasmid. According to miRmap (http://mirmap.ezlab.org), the 2 binding sites of miR-211-3p were mutated and the mutated sequences of TUSC7 were subcloned into pcDNA3.1 vector, i,e., TUSC(mut). 293T cells were seeded in 24well plates at a density of $2.0 \times 10^{5}$ cells per well, followed growth for $24 \mathrm{~h}$ before transfection. Then, each well was cotransfected with pMIR-REPORT reporter plasmid, NC or miR-211-3p mimics, TUSC (wt) or TUSC (mut) and 10 ng internal control vector pRL-SV40 (Promega, Madison, WI, USA). Cell lysates were harvested after $24 \mathrm{~h}$ transfection, followed by the measurement of firefly and renilla luciferase activities by the DualLuciferase Reporter Assay System (Promega). The value of relative luciferase activity indicates the firefly luciferase activity normalized to that of renilla for each assay.

\section{Statistical Analysis}

Student's t-test (two-tailed), One-way ANOVA, Kaplan-Meier curve, and Cox-regression were performed to analyze the data using SPSS 18.0 software. $P$ values less than 0.05 were considered statistically significant.

\section{Results}

\section{TUSC7 is downregulated in CRC}

We first investigated expression of TUSC7 by qRT-PCR in a cohort of 63 CRC patients. As shown in Fig. 1A, TUSC7 was downregulated in most CRC tissues (53 of 63 patients) compared with adjacent non-tumor tissues $(P<0.01)$. Then we analyzed the association between TUSC7 expression and clinicopathological features of CRC patients. We found TUSC7 expression level was lower in CRC tissues larger than $3 \mathrm{~cm}$, while there was no significant association between TUSC7 expression levels with other clinical features (Table 1).

To determine whether TUSC7 expression is associated with survival, CRC patients were divided into two different groups (high and low) according to TUSC7 expression level. As indicated in Fig. 1B, CRC patients with high expression of TUSC7 had better survival (HR = $0.342,95 \%$ CI: $0.120-0.972, P=0.044$ ) compared with those with low TUSC7 expression.

\section{TUSC7 inhibits CRC cell proliferation}

The significant decrease of TUSC7 in CRC prompted us to explore the possible biological roles of TUSC7 in CRC. To achieve this, we ectopically overexpressed TUSC7 in HCT116 and SW480 cell lines (Fig. 2A). CCK8 and EdU assays demonstrated that overexpression of TUSC7 significantly decreased proliferation rate in both HCT116 and SW480 cells (Fig. 2B, C, and D). Colony formation assay showed that after overexpression of TUSC7, colony formation ability was significantly decreased in HCT116 cells (E). 


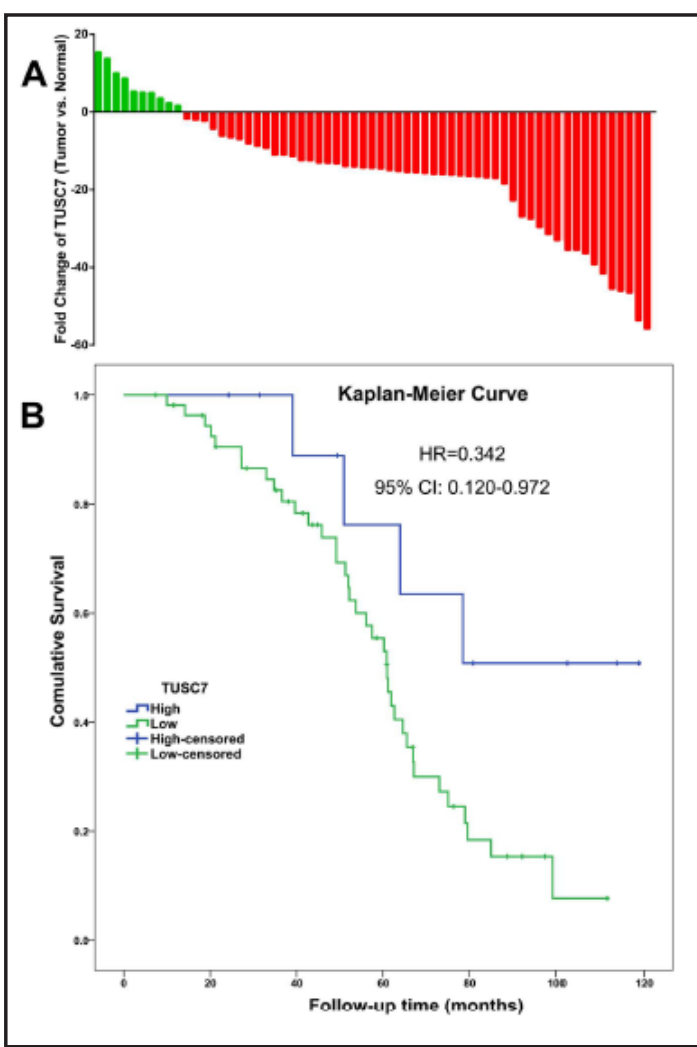

Fig. 1. TUSC7 is downregulated in most CRC tissues compared with adjacent nontumor tissues (53 of 63 patients, $P<0.01$ ). Compared with patients with low TUSC7 expression, patients with high TUSC7 expression have better survival (HR $=0.342,95 \% \mathrm{CI}: 0.120$ 0.972, $P=0.044$ ).
Table 1. Correlation between TUSC7 expression and clinicopathologic characteristics. * significant association

\begin{tabular}{|c|c|c|c|c|}
\hline Characteristics & & Number & Fold change & $p$ values \\
\hline & & 63 & & \\
\hline \multirow[t]{3}{*}{ Age } & & & & 0.596 \\
\hline & $\geq 60$ & 34 & -10.73 & \\
\hline & $<60$ & 29 & -15.69 & \\
\hline \multirow[t]{3}{*}{ Gender } & & & & 0.888 \\
\hline & Male & 37 & -15.3 & \\
\hline & Female & 26 & -9.76 & \\
\hline \multirow[t]{3}{*}{ Family History } & & & & 0.253 \\
\hline & Positive & 17 & -6.56 & \\
\hline & Negative & 46 & -15.4 & \\
\hline \multirow[t]{3}{*}{ Tumor Site } & & & & 0.632 \\
\hline & Below Decending Colon & 49 & -14.85 & \\
\hline & Above Sigmoid Colon & 14 & -6.59 & \\
\hline \multirow[t]{3}{*}{ Tumor Size $(\mathrm{Cm})$} & & & & $0.012^{*}$ \\
\hline & $\geq 3$ & 18 & -19.17 & \\
\hline & $<3$ & 45 & -10.55 & \\
\hline \multirow[t]{3}{*}{ Differentiation } & & & & 0.491 \\
\hline & Poor & 25 & -13.87 & \\
\hline & Moderate Or High & 38 & -12.45 & \\
\hline \multirow[t]{3}{*}{ T Stage } & & & & 0.057 \\
\hline & Entire Serosa Invasion & 52 & -12.6 & \\
\hline & Subserous Invasion & 11 & -14.94 & \\
\hline \multirow[t]{3}{*}{ N Stage } & & & & 0.775 \\
\hline & Positive & 28 & -18.81 & \\
\hline & Negative & 35 & -15.05 & \\
\hline \multirow[t]{3}{*}{ M Stage } & & & & 0.756 \\
\hline & Positive & 11 & -13.32 & \\
\hline & Negative & 52 & -12.95 & \\
\hline
\end{tabular}

TUSC7 induces cell cycle arrest

To further analyze whether TUSC7 regulate cell cycle, we performed PI staining followed by flow cytometry analysis. As indicated in Fig. 3A, B, overexpression induced G1 cell cycle arrest in both HCT116 and SW480 cells. While the percentage of S phase and G2 phase were decreased after TUSC7 overexpression.

\section{TUSC7 inhibits CRC cell invasion}

The matrigel assay was performed to investigate the effect of TUSC7 on CRC cell invasion ability. As shown in Fig. 3, after transfection of TUSC7 the invasion ability was significantly inhibited in HCT116 and SW480 cells (Fig. 3C, D).

Silence of TUSC7 promotes proliferation of CRC cells

To silence TUSC7, 3 siRNA sequences were designed and synthesized. As shown, TUSC7 expression was decreased by 3 siRNAs and the siRNA3\# had best inhibitory effect and siRNA3 was selected for further experiments (Fig. 4A). CCK8 and colony formation assays revealed that silence of TUSC7 increased cell proliferation rate and colony formation ability in HCT116 cells (Fig. 4B, C).

TUSC7 downregulates CDK6 by sponging miR-211

Recently, evidence has proved that IncRNA could exert biological function through competing endogenous RNA mechanism, namely competitively binding with miRNAs. By 


\section{Cellular Physiology Cell Physiol Biochem 2017;41:635-644 \begin{tabular}{ll|l} 
DOI: 10.1159/000457938 & $\begin{array}{l}\text { O } 2017 \text { The Author(s). Published by S. Karger AG, Basel } \\
\text { www.karger.com/cpb }\end{array}$ \\
\cline { 2 - 4 }
\end{tabular} Xu/Zhao/Zhang: TUSC7 Sponges MiR-211-3p in CRC}

Fig. 2. TUSC7 is overexpressed in CRC cells (A, HCT116 cells). CCK8 assay showed that ectopic expression of TUSC7 significantly inhibited proliferate rate of CRC cells (B, HCT116 cells; C: SW480 cells). EdU assay showed that ectopic expression of TUSC7 decreased the percentage of viable cells (D, HCT116 cells, $32 \%$ vs. $11 \%$ ). Colony formation ability was also inhibited by TUSC7 (E). ${ }^{*} P<0.05$; ** $P<0.01$.

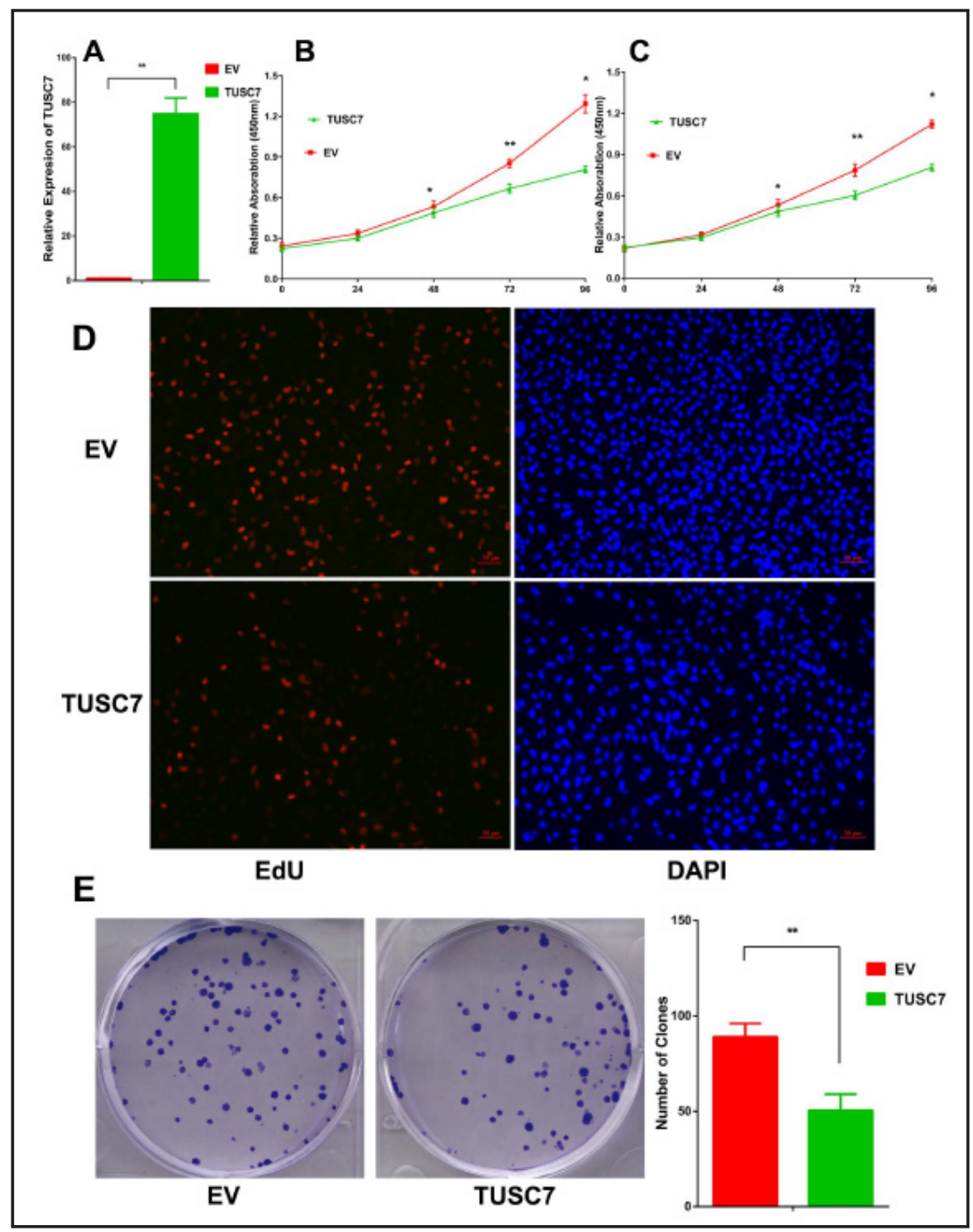

bioinformatics analysis, we found there were 2 binding sites of miR-211-3p within sequence of TUSC7. Additionally, it has also been reported that miR-211-3p played as an oncogene in CRC and miR-211-3p could promote cell proliferation by targeting CDK6 in CRC cells [15]. Thus, we hypothesized that TUSC7 might have a ceRNA mechanism in CRC, namely TUSC7 promotes proliferation by sponging miR-211-3p.

In a cohort of CRC patients, we first analyzed the expression of TUSC7 and miR-211-3p. qRT-PCR revealed that TUSC7 and miR-211-3p were negatively correlated $(\mathrm{R}=-0.476, P=$ 0.019 , Fig. 5A). However, overexpression did not affect the expression level of miR-221-3p (Fig. 5B). It has been reported that miR-211-3p has a pro-oncogenic role in CRC and we found that after transfection of miR-211-3p mimics, cell proliferation rate increased in CRC cells compared with NC (Fig. 5C, D). Then, we overexpressed TUSC7 and miR-211-3p in HCT116 cells, respectively. In consistence with previous reports, CDK6 expression was decreased at RNA and protein level (Fig. 5E, F) after miR-211-3p overexpression. On the other hand, after overexpression of TUSC7, CDK6 expression increased accordingly.

Cell fraction assay was performed to identify cellular location of TUSC7. As shown, most of TUSC7 transcripts were located in cytoplasm (Fig. 5H). Furthermore, we determined whether TUSC7 act as sponge to prevent miR-211-3p induced degradation of CDK6 by dual luciferase reporter assay. As indicated in Fig. 5H, miR-211-3p decreased the luciferase activity, while ectopic expression of TUSC7 restored the luciferase activity which was reduced by miR-211-3p. These results showed that TUSC7 could sponge endogenous miR- 


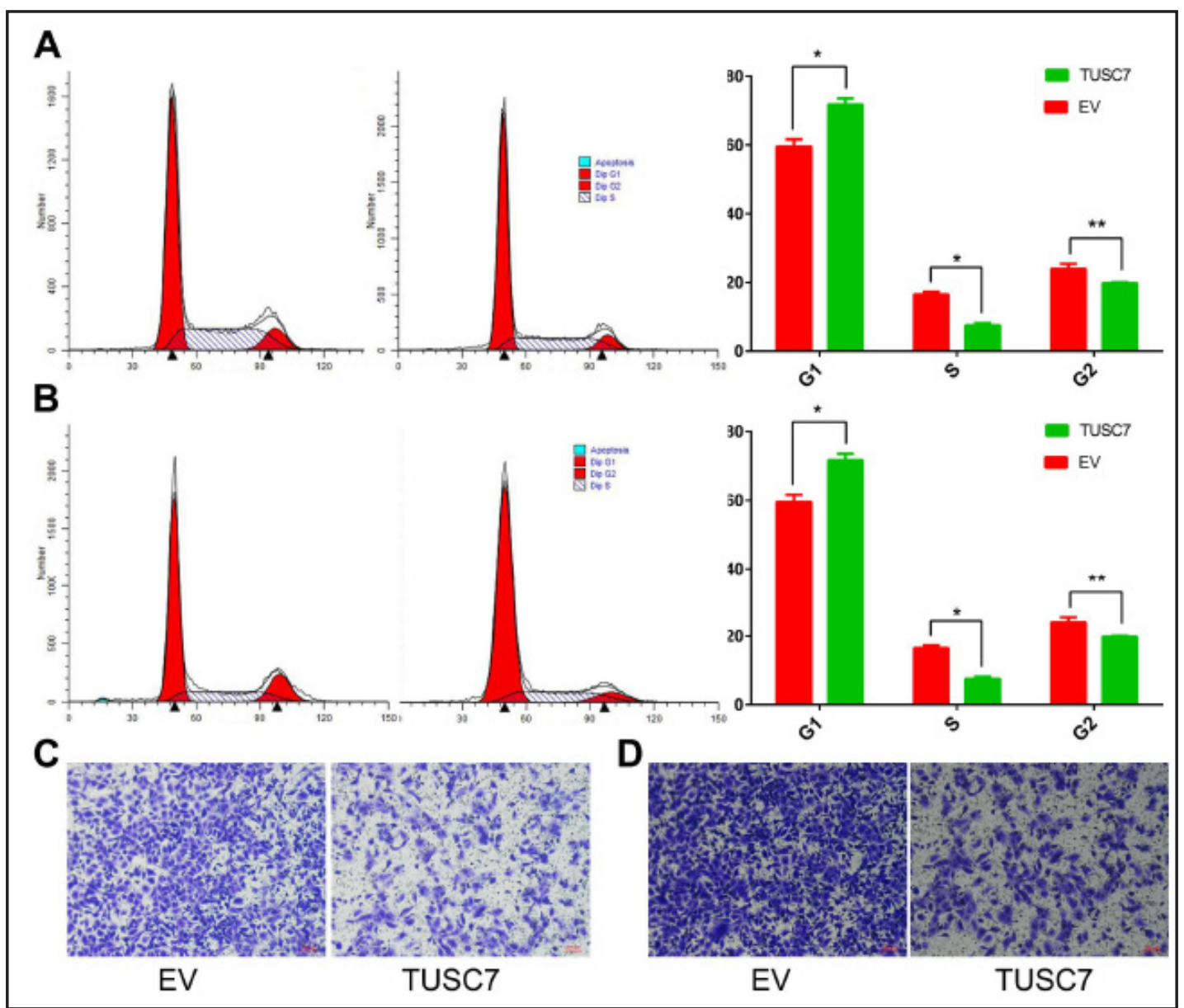

Fig. 3. Overexpression of TUSC7 increases percentage of G1 phase cells, while percentage of S and G2 phase cells decreased (A, HCT116 cells; B: SW480 cells). Cell invasion ability was inhibited after overexpression of TUSC7(C, HCT116 cells; D: SW480 cells). ${ }^{*} P<0.05 ;{ }^{* *} P<0.01$.

211-3p and prevent it from inhibiting luciferase activity. On the contrast, when the 2 binding sites were mutated, TUSC7 (mut) lost the ability of binding miR-211-2p. According to ceRNA hypothesis, genes in ceRNA relationship would be positively correlated. Thus, we analyzed the expression levels of TUSC7 and CDK6 in an independent dataset of 152 CRC patients [16]. As shown, TUSC7 and CDK6 were significantly positively correlated $(\mathrm{R}=0.590, P<0.01$, Fig. 5I), which supported our hypothesis.

\section{Discussion}

Dysregulated lncRNAs have been reported in many types of cancer and these lncRNAs have complex molecular mechanisms, which have been reviewed elsewhere $[17,18]$. The ceRNA hypothesis is proposed by Pandolfi PP, which enriches the cross-talk between RNA transcripts $[19,20]$. In the current study, we found TUSC7 promoted CRC cells proliferation by acting as competing endogenous sponge of miR-211-3p.

The importance of lncRNAs in human diseases might be associated with their ability to modulate cellular function with different mechanisms [21-23]. In the aspect of gene expression, lncRNA could exert their function at different levels. At the posttranscriptional level, ceRNA is a common mechanism and various lncRNAs are reported to sponge lncRNAs, such as HOTAIR [24], PTENP1 [25], and NEAT1 [26]. 
Fig. 4. TUSC7 was efficiently silenced by siRNAs (A) and HCT-116 cell proliferation rate was also increased after TUSC7 silence (B). The colony formation ability was also increased after silence of TUSC7 in HCT-116 cells (C). * $\mathrm{P}<0.05 ; * * \mathrm{P}<0.01$.
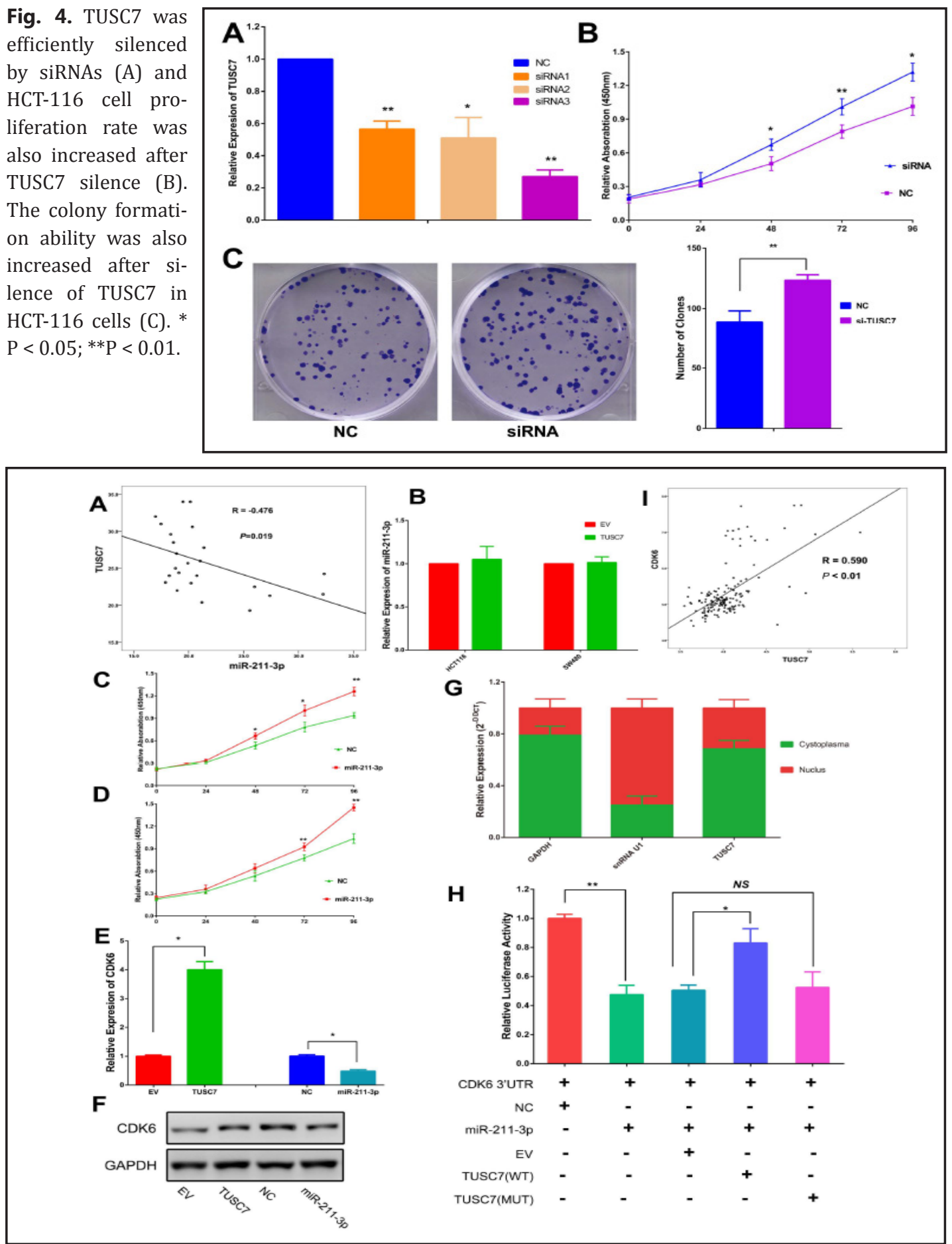

Fig. 5. Expression levels between TUSC7 and miR-211-3p were negatively correlated in CRC tissues (A). The expression level of miR-211-3p did not change significantly after overexpression of TUSC7 (B). Compared with NC, miR-211-3p mimics inhibited proliferation rate of HCT116 (C) and SW480 (D) cells. Overexpression of TUSC7 increases the expression of CDK6, while miR-211-3p decreases the expression of CDK6 in RNA (E) and protein level (F). Cell fraction assay showed that most TUSC7 transcripts were located in cytoplasm (G). Ectopic expression of TUSC7 (WT) restored the luciferase activity reduced by miR-211-3p, while after mutation of binding sites of miR-211-3p fails to rescue the reduction $(\mathrm{H})$. In a dataset of 152 samples, the expression levels of TUSC7 and CDK6 are positively correlated (I). TUSC(WT): wide type sequence of TUSC7; TUSC(MUT): TUSC7 sequence with 2 mutated miR-211-3p binding sites $* P<0.05$; ${ }^{* *} P<0.01$. 


\section{Cellular Physiology Cell Physiol Biochem 2017;41:635-644

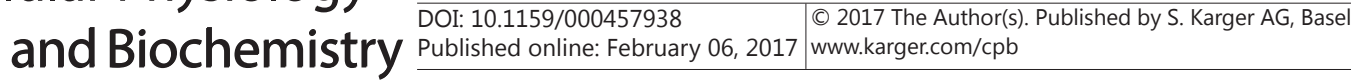 \\ Xu/Zhao/Zhang: TUSC7 Sponges MiR-211-3p in CRC}

The role of mir-211-3p differs among different cancers [27, 28]. Previous data have demonstrated miR-211-3p is an important oncogenic miRNA in CRC, which is significantly upregulated in CRC and high expression of miR-211-3p indicates poor survival [29]. By PCR assay we found miR-211-3p and TUSC7 were negatively correlated. It has been reported that miR-211-3p promoted CRC cell proliferation by targeting CDK6 [15]. And according to an independent dataset $[12,16]$, TUSC7 and CDK6 are positively correlated. Thus, these associations indicated that TUSC7 might have ceRNA mechanism. Then we further found that CDK6 expression increased after TUSC7 overexpression. Luciferase reporter assay revealed that TUSC7(wt) could rescue miR-211-3p induced reduction of luciferase activity, but there was no significant difference when miR-211-3p binding sites were mutated. Thus, these lines of evidence convinced the ceRNA mechanism of TUSC7.

In gastric cancer, TUSC7 is reported as a direct downstream target of p53 and function as a tumor suppressor by downregulate miR-23b [12]. In addition, TUSC7 was also reported to function through ceRNA mechanism in hepatocellular carcinoma by sponging miR-10a [30]. In the current study, we also found TUSC7 was downregulated in CRC tissues compared with adjacent non-tumor tissues and high expression of TUSC7 indicated better survival, suggesting TUSC7 could be a potential tumor suppressor in CRC. We found TUSC7 could promote proliferation by sponging miR-211-3p in CRC. Considering that there are many targets of miR-211-3p, it is highly possible that TUSC7 could regulate expression of other genes. Additionally, given the complex mechanisms of IncRNA, TUSC7 might have other molecular mechanism and more efforts are warranted.

In summary, our data demonstrate that TUSC7 is downregulated in CRC and high expression of TUSC7 indicates better survival. In vitro experiments proved that TUSC7 inhibits cell proliferation and sponge miR-211-3p in CRC cells.

\section{Disclosure Statement}

The authors have declared no conflict of interest.

\section{References}

1 Jemal A, Bray F, Center MM, Ferlay J, Ward E, Forman D: Global cancer statistics. CA Cancer J Clin 2011;61:69-90.

2 Parkin DM, Bray F, Ferlay J, Pisani P: Global cancer statistics, 2002. CA Cancer J Clin 2005;55:74-108.

3 Brenner H, Kloor M, Pox CP: Colorectal cancer. Lancet 2014;383:1490-1502.

4 Markowitz SD, Bertagnolli MM: Molecular origins of cancer: Molecular basis of colorectal cancer. N Engl J Med 2009;361:2449-2460.

5 Ponting CP, Oliver PL, Reik W: Evolution and functions of long noncoding RNAs. Cell 2009;136:629-641.

6 Esteller M: Non-coding RNAs in human disease. Nat Rev Genet 2011;12:861-874.

7 Mercer TR, Dinger ME, Mattick JS: Long non-coding RNAs: insights into functions. Nat Rev Genet 2009;10:155-159.

8 Qiu MT, Hu JW, Yin R, Xu L: Long noncoding RNA: an emerging paradigm of cancer research. Tumour Biol 2013;34:613-620.

-9 Tsai MC, Spitale RC, Chang HY: Long intergenic noncoding RNAs: new links in cancer progression. Cancer Res 2011;71:3-7.

10 Bartel DP: MicroRNAs: target recognition and regulatory functions. Cell 2009;136:215-233.

11 Ling H, Spizzo R, Atlasi Y, Nicoloso M, Shimizu M, Redis RS, Nishida N, Gafa R, Song J, Guo Z, Ivan C, Barbarotto E, De Vries I, Zhang X, Ferracin M, Churchman M, van Galen JF, Beverloo BH, Shariati M, Haderk F, Estecio MR, Garcia-Manero G, Patijn GA, Gotley DC, Bhardwaj V, Shureiqi I, Sen S, Multani AS, Welsh J, Yamamoto K, Taniguchi I, Song MA, Gallinger S, Casey G, Thibodeau SN, Le Marchand L, Tiirikainen M, Mani SA, Zhang W, Davuluri RV, Mimori K, Mori M, Sieuwerts AM, Martens JW, Tomlinson I, Negrini M, BerindanNeagoe I, Foekens JA, Hamilton SR, Lanza G, Kopetz S, Fodde R, Calin GA: CCAT2, a novel noncoding RNA mapping to 8q24, underlies metastatic progression and chromosomal instability in colon cancer. Genome Res 2013;23:1446-1461. 


\section{Cellular Physiology Cell Physiol Biochem 2017;41:635-644

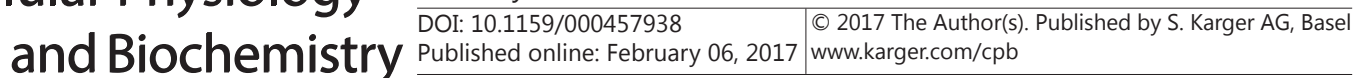 \\ Xu/Zhao/Zhang: TUSC7 Sponges MiR-211-3p in CRC}

12 Qi P, Xu MD, Shen XH, Ni SJ, Huang D, Tan C, Weng WW, Sheng WQ, Zhou XY, Du X: Reciprocal repression between TUSC7 and miR-23b in gastric cancer. Int J Cancer 2015;137:1269-1278.

13 Cong M, Li J, Jing R, Li Z: Long non-coding RNA tumor suppressor candidate 7 functions as a tumor suppressor and inhibits proliferation in osteosarcoma. Tumour Biol DOI:10.1007/s13277-015-4414-y.

14 VanGuilder HD, Vrana KE, Freeman WM: Twenty-five years of quantitative PCR for gene expression analysis. Biotechniques 2008;44:619-626.

-15 Xia B, Yang S, Liu T, Lou G: miR-211 suppresses epithelial ovarian cancer proliferation and cell-cycle progression by targeting Cyclin D1 and CDK6. Mol Cancer 2015;14:57.

-16 Takahashi H, Ishikawa T, Ishiguro M, Okazaki S, Mogushi K, Kobayashi H, Iida S, Mizushima H, Tanaka H, Uetake H, Sugihara K: Prognostic significance of Traf2- and Nck- interacting kinase (TNIK) in colorectal cancer. BMC Cancer 2015;15:794.

17 Han P, Chang CP: Long non-coding RNA and chromatin remodeling. RNA Biol 2015;12:1094-1098.

18 Roberts TC, Morris KV, Weinberg MS: Perspectives on the mechanism of transcriptional regulation by long non-coding RNAs. Epigenetics 2014;9:13-20.

19 Salmena L, Poliseno L, Tay Y, Kats L, Pandolfi PP: A ceRNA hypothesis: the Rosetta Stone of a hidden RNA language? Cell 2011;146:353-358.

20 Karreth FA, Reschke M, Ruocco A, Ng C, Chapuy B, Leopold V, Sjoberg M, Keane TM, Verma A, Ala U, Tay Y, Wu D, Seitzer N, Velasco-Herrera Mdel C, Bothmer A, Fung J, Langellotto F, Rodig SJ, Elemento O, Shipp MA, Adams DJ, Chiarle R, Pandolfi PP: The BRAF pseudogene functions as a competitive endogenous RNA and induces lymphoma in vivo. Cell 2015;161:319-332.

21 Gupta RA, Shah N, Wang KC, Kim J, Horlings HM, Wong DJ, Tsai MC, Hung T, Argani P, Rinn JL, Wang Y, Brzoska P, Kong B, Li R, West RB, van de Vijver MJ, Sukumar S, Chang HY: Long non-coding RNA HOTAIR reprograms chromatin state to promote cancer metastasis. Nature 2010;464:1071-1076.

-22 Roberts TC, Wood MJ: Therapeutic targeting of non-coding RNAs. Essays Biochem 2013;54:127-145.

-23 Wahlestedt C: Targeting long non-coding RNA to therapeutically upregulate gene expression. Nat Rev Drug Discov 2013;12:433-446.

24 Liu XH, Sun M, Nie FQ, Ge YB, Zhang EB, Yin DD, Kong R, Xia R, Lu KH, Li JH, De W, Wang KM, Wang ZX: Lnc RNA HOTAIR functions as a competing endogenous RNA to regulate HER2 expression by sponging miR331-3p in gastric cancer. Mol Cancer 2014;13:92.

25 Poliseno L, Salmena L, Zhang J, Carver B, Haveman WJ, Pandolfi PP: A coding-independent function of gene and pseudogene mRNAs regulates tumour biology. Nature 2010;465:1033-1038.

26 Sun C, Li S, Zhang F, Xi Y, Wang L, Bi Y, Li D: Long non-coding RNA NEAT1 promotes non-small cell lung cancer progression through regulation of miR-377-3p-E2F3 pathway. Oncotarget DOI: 10.18632/ oncotarget.10108.

-27 Ye L, Wang H, Liu B: miR-211 promotes non-small cell lung cancer proliferation by targeting SRCIN1. Tumour Biol 2016;37:1151-1157.

28 Wang CY, Hua L, Sun J, Yao KH, Chen JT, Zhang JJ, Hu JH: MiR-211 inhibits cell proliferation and invasion of gastric cancer by down-regulating SOX4. Int J Clin Exp Pathol 2015;8:14013-14020.

-29 Wu X, He X, Li S, Xu X, Chen X, Zhu H: Long Non-Coding RNA ucoo2kmd.1 Regulates CD44-Dependent Cell Growth by Competing for miR-211-3p in Colorectal Cancer. PLoS One 2016;11:e0151287.

30 Wang Y, Liu Z, Yao B, Dou C, Xu M, Xue Y, Ding L, Jia Y, Zhang H, Li Q Tu K, Jiao Y, Liu Q, Guo C: Long noncoding RNA TUSC7 acts a molecular sponge for miR-10a and suppresses EMT in hepatocellular carcinoma. Tumour Biol DOI:10.1007/s13277-016-4892-6. 